\title{
Synthesis of the character impact compound raspberry ketone and additional flavoring phenylbutanoids of biotechnological interest with Corynebacterium glutamicum
}

\author{
Lars Milke ${ }^{1}$, Mario Mutz ${ }^{1}$ (1) and Jan Marienhagen ${ }^{1,2,3^{*}}$ (])
}

\begin{abstract}
Background: The phenylbutanoid 4-(4-hydroxyphenyl)butan-2-one, commonly known as raspberry ketone, is responsible for the typical scent and flavor of ripe raspberries. Chemical production of nature-identical raspberry ketone is well established as this compound is frequently used to flavor food, beverages and perfumes. However, high demand for natural raspberry ketone, but low natural abundance in raspberries, render raspberry ketone one of the most expensive natural flavoring components.

Results: In this study, Corynebacterium glutamicum was engineered for the microbial synthesis of the character impact compound raspberry ketone from supplemented $p$-coumaric acid. In this context, the NADPH-dependent curcumin/dihydrocurcumin reductase CurA from Escherichia coli was employed to catalyze the final step of raspberry ketone synthesis as it provides a hitherto unknown benzalacetone reductase activity. In combination with a 4-coumarate: CoA ligase from parsley (Petroselinum crispum) and a monofunctional benzalacetone synthase from Chinese rhubarb (Rheum palmatum), CurA constitutes the synthetic pathway for raspberry ketone synthesis in C. glutamicum. The resulting strain accumulated up to $99.8 \mathrm{mg} / \mathrm{L}(0.61 \mathrm{mM})$ raspberry ketone. In addition, supplementation of other phenylpropanoids allowed for the synthesis of two other naturally-occurring and flavoring phenylbutanoids, zingerone $(70 \mathrm{mg} / \mathrm{L}, 0.36 \mathrm{mM})$ and benzylacetone $(10.5 \mathrm{mg} / \mathrm{L}, 0.07 \mathrm{mM})$.
\end{abstract}

Conclusion: The aromatic product portfolio of C. glutamicum was extended towards the synthesis of the flavoring phenylbutanoids raspberry ketone, zingerone and benzylacetone. Key to success was the identification of CurA from E. coli having a benzalacetone reductase activity. We believe, that the constructed C. glutamicum strain represents a versatile platform for the production of natural flavoring phenylbutanoids at larger scale.

Keywords: NADPH-dependent curcumin reductase, Benzalacetone reductase, Corynebacterium glutamicum, Raspberry ketone, Metabolic engineering, Character impact compound

*Correspondence: j.marienhagen@fz-juelich.de

${ }^{1}$ Institute of Bio- and Geosciences, IBG-1: Biotechnology, Forschungszentrum Jülich GmbH, 52425 Jülich, Germany

Full list of author information is available at the end of the article

\begin{abstract}
Introduction
The phenylbutanoid character impact compound raspberry ketone (4-(4-hydroxyphenyl)butan-2-one, RK) defines the typical scent and taste of raspberries. Thus, it is utilized by food and beverage industries to flavor beverages and foods, e.g. pudding, yogurt or sweets $[1,2]$. In addition, its presumed activity as an anti-obesity or skinwhitening agent, drew consumers interest, although a
\end{abstract}

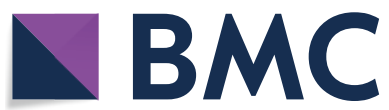

(c) The Author(s) 2020. This article is licensed under a Creative Commons Attribution 4.0 International License, which permits use, sharing, adaptation, distribution and reproduction in any medium or format, as long as you give appropriate credit to the original author(s) and the source, provide a link to the Creative Commons licence, and indicate if changes were made. The images or other third party material in this article are included in the article's Creative Commons licence, unless indicated otherwise in a credit line to the material. If material is not included in the article's Creative Commons licence and your intended use is not permitted by statutory regulation or exceeds the permitted use, you will need to obtain permission directly from the copyright holder. To view a copy of this licence, visit http://creativeco mmons.org/licenses/by/4.0/. The Creative Commons Public Domain Dedication waiver (http://creativecommons.org/publicdomain/ zero/1.0/) applies to the data made available in this article, unless otherwise stated in a credit line to the data. 
potential toxicity of this compound for humans has not yet been clarified [2-6].

Different strategies can be followed to obtain RK, e.g. extraction from natural plant material or chemical synthesis. Adversely, the natural concentration of RK in raspberries is not only very low ( $1-4 \mathrm{mg} / \mathrm{kg}$ ), but also subject to seasonal and regional fluctuations, leading to high product costs of 3000-20,000 US\$ per kg of natural, extracted RK $[1,7,8]$. Alternatively, RK can be chemically synthesized, but any RK produced by such processes is only considered as a nature-identical flavoring substance according to EU and US regulations, which no longer meets customers' demands [9-11]. Contrary to this, RK obtained from microbial synthesis is regarded as natural. Thus, microbial synthesis represents a promising approach for the sustainable production of natural RK. Prerequisite for establishing a microbial RK production process is the functional introduction of the natural biosynthesis pathway from the plant into a heterologous host.

In raspberry plants, RK synthesis starts from L-phenylalanine, which is provided by the shikimate pathway [12]. From there, L-phenylalanine is non-oxidatively deaminated by a phenylalanine ammonia lyase (PAL), yielding the phenylpropanoid cinnamic acid, which is subsequently hydroxylated towards $p$-coumaric acid $(p C A)$. This compound in turn undergoes CoA-activation catalyzed by a 4-coumarate: CoA ligase (4CL, Fig. 1). The activated thioester is then condensed with one molecule of malonyl-CoA by a benzalacetone synthase (BAS), a type III polyketide synthase (PKS), yielding the diketide intermediate $p$-hydroxybenzalacetone ( $p \mathrm{HBA})$. Finally, a NADPH-dependent benzalacetone reductase (BAR) reduces $p \mathrm{HBA}$ to $\mathrm{RK}$.

First studies on microbial RK production from supplemented $p \mathrm{CA}$ using BAS from Chinese rhubarb (Rheum palmatum) and CHS from raspberry (Rubus idaeus), respectively, reported product titers below $10 \mathrm{mg} / \mathrm{L}(0.06 \mathrm{mM})$ when using Escherichia coli or Saccharomyces cerevisiae as host strains [1, 13]. Interestingly, both studies relied on endogenous BAR activities by unknown endogenous reductase(s) in the respective host, rendering heterologous expression of a BAR-encoding gene unnecessary. Only recently, synthesis of up to $91 \mathrm{mg} / \mathrm{L}(0.55 \mathrm{mM})$ RK was demonstrated using E. coli BL21(DE3), which was developed for the expression of bas from R. palmatum and rzs1 from raspberry $[8,14]$. The latter gene codes for the raspberry ketone/zingerone synthase RZS1 (RZS1 ${ }_{R i}$, UniProt ID: G1FCG0), which provides the required BAR activity.

Since various type III PKS-encoding genes of plant origin (encoding for stilbene synthases, chalcone synthases and a pentaketide chromone synthase) have

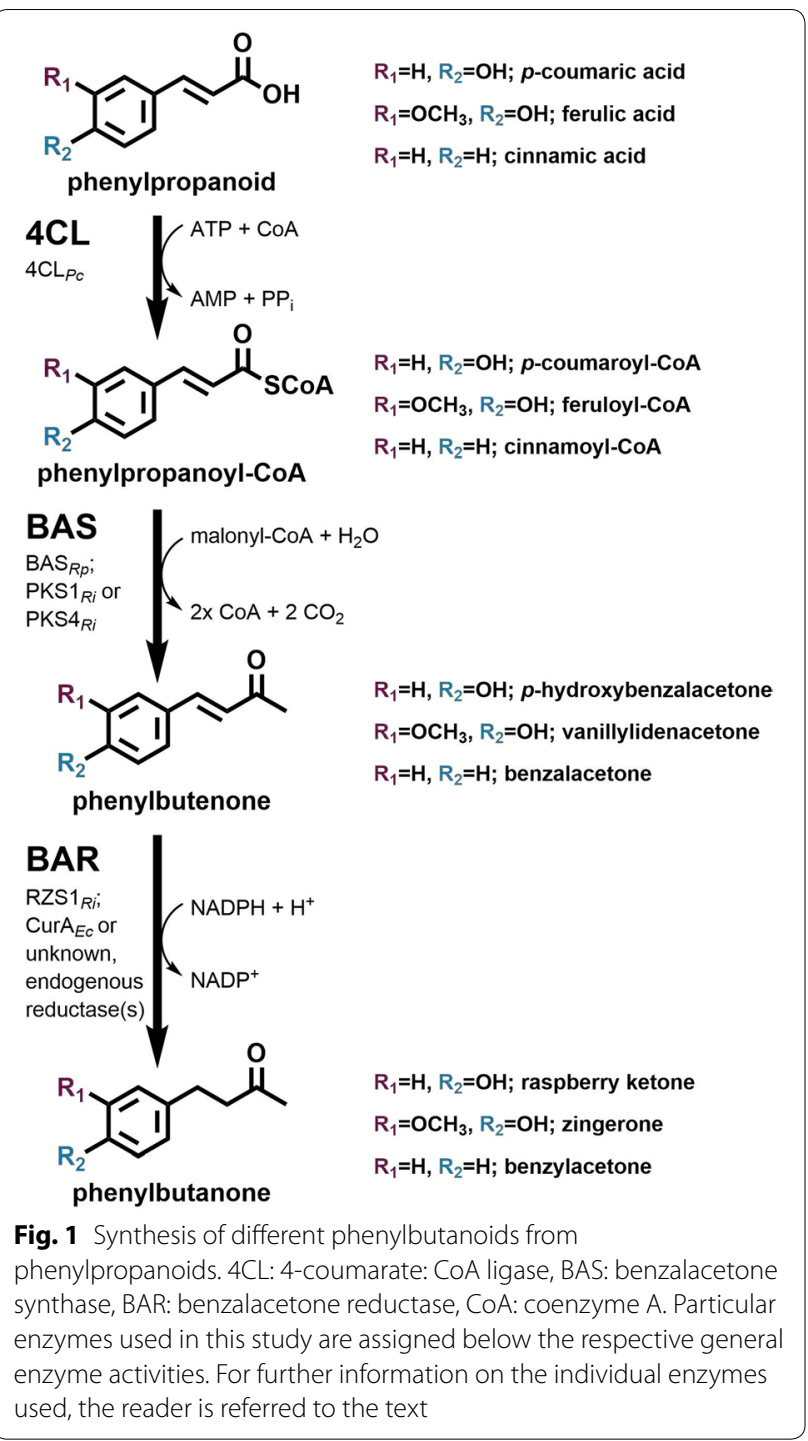

been functionally expressed in Corynebacterium glutamicum previously, it is reasonable to assume that this is also true for a type III PKS gene providing BAS activity $[15,16]$.

In this context, $C$. glutamicum strains have been tailored towards increased malonyl-CoA supply for efficient synthesis of plant polyphenols and polyketides [16-18]. This was necessary, as typically only low intracellular concentrations of the unstable fatty acid precursor malonyl-CoA are maintained in microorganisms as its synthesis is strictly regulated, limiting overall product formation [19]. Although only one molecule of malonyl-CoA is required for the synthesis of one RK molecule, a C. glutamicum strain with increased malonyl-CoA availability is predestined for also establishing a heterologous pathway for the synthesis of RK. 
In this study, we present the construction of a microbial C. glutamicum cell factory for the synthesis of the flavoring phenylbutanoids RK, zingerone and benzylacetone. Additionally, we identified a hitherto unknown BAR activity of the NADPH-dependent curcumin/dihydrocurcumin reductase CurA from E. coli allowing for the reduction of diketide intermediates.

\section{Results}

\section{Cytotoxicity of $p$-hydroxybenzalacetone and raspberry} ketone

In preparation of establishing a heterologous RK biosynthesis pathway from supplemented $p C A$, intermediate $(p \mathrm{HBA})$ and product $(\mathrm{RK})$ cytotoxicity on the designated host $C$. glutamicum was investigated. For this purpose, the strain C. glutamicum M-CoA, previously constructed for providing increased malonyl-CoA levels [16], was cultivated in CGXII medium with $4 \%$ glucose supplemented with different concentrations ranging from 0 to $1 \mathrm{~g} / \mathrm{L}(6.17 \mathrm{mM}) \mathrm{pHBA}$ and RK $(6.1 \mathrm{mM})$ using the BioLector microbioreactor system (Fig. 2). Concentrations $\geq 125 \mathrm{mg} / \mathrm{L}(0.77 \mathrm{mM}) p \mathrm{HBA}$ negatively affected microbial growth up to complete growth inhibition in the presence of $1 \mathrm{~g} / \mathrm{L}(6.17 \mathrm{mM}) \mathrm{pHBA}$. Bearing the designated supplementation of $5 \mathrm{mM} p \mathrm{CA}$ as precursor for RK synthesis in mind, resembling the standard production conditions for the synthesis of $p$ CA-derived plant polyphenols using C. glutamicum, such toxic concentrations cannot be reached [18]. In contrast, no significant negative impact on growth could be observed upon supplementation of up to $1 \mathrm{~g} / \mathrm{L}(6.1 \mathrm{mM}) \mathrm{RK}$.
Previous studies utilizing either E. coli or S. cerevisiae for microbial RK synthesis demonstrated that both hosts provide an endogenous BAR activity $[1,13]$. Hence, supernatants from the C. glutamicum microbioreactor cultivations performed in the context of the $p \mathrm{HBA}$ cytotoxicity experiments, were analyzed by HPLC for the presence of potentially accumulating RK. Indeed, RK was detected in all samples from cultivations supplemented with $\geq 125 \mathrm{mg} / \mathrm{L}(0.77 \mathrm{mM}) p \mathrm{HBA}$ reaching a maximum of $15.4 \mathrm{mg} / \mathrm{L}$ (0.094 mM) RK when $500 \mathrm{mg} / \mathrm{L}$ (3.09 mM) $p$ HBA was present in the microbioreactor cultivations. Interestingly, even though the $C$. glutamicum cells did not grow in the presence of $1 \mathrm{~g} / \mathrm{L}(6.17 \mathrm{mM}) p \mathrm{HBA}$, up to $9.3 \mathrm{mg} / \mathrm{L}(0.057 \mathrm{mM}) \mathrm{RK}$ were formed. This particular experiment was repeated without cells to verify that $p \mathrm{HBA}$ reduction yielding $\mathrm{RK}$ is due to the presence of the C. glutamicum cells conferring an endogenous BAR activity and not the result of a spontaneous reduction under the selected cultivation conditions in CGXII medium. This control experiment showed that RK formation was only detectable in the presence of C. glutamicum cells. Therefore, a yet unknown endogenous BAR activity can also be ascribed to C. glutamicum.

\section{The curcumin reductase CurA from $E$. coli improves the BAR activity in C. glutamicum}

With the aim to increase the endogenous BAR activity and to establish the full RK pathway in C. glutamicum, heterologous genes coding for BAS and BAR enzymes were episomally introduced into this bacterium. For this purpose, a codon-optimized gene variant encoding BAS
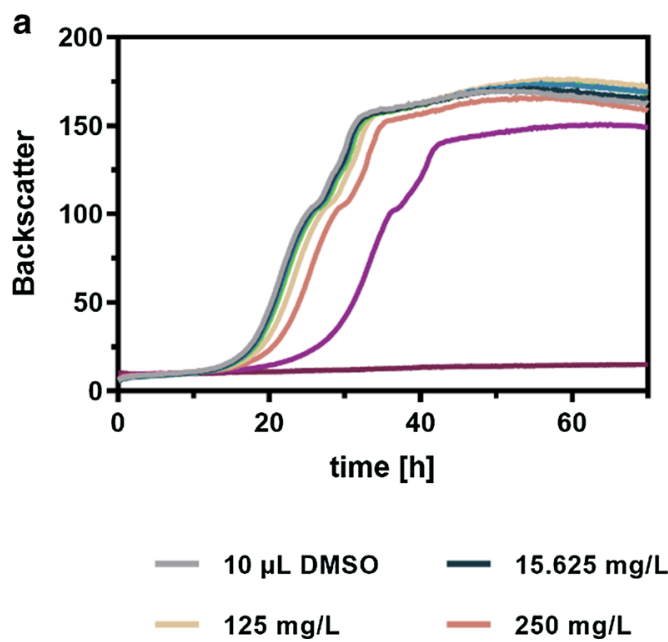
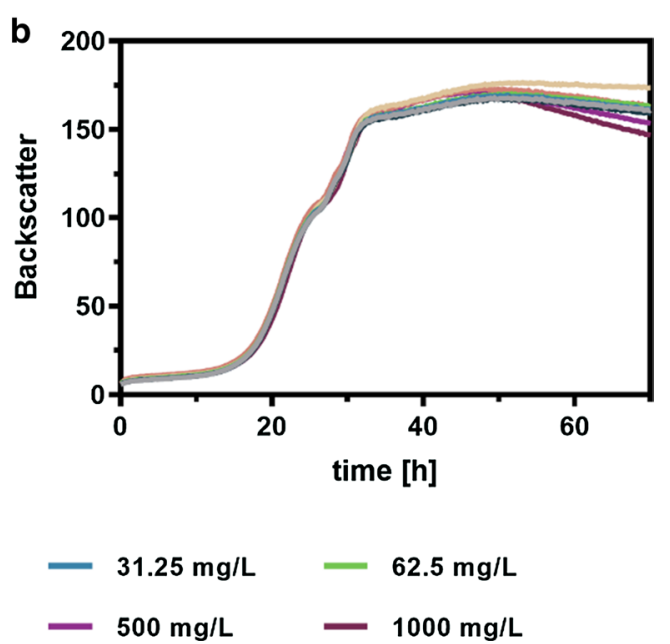

Fig. 2 Cytotoxic effects of $\mathbf{a} p$-hydroxybenzalacetone and $\mathbf{b}$ raspberry ketone on growth of C. glutamicum. C. glutamicum M-CoA was cultivated in CGXII medium with $4 \%$ glucose supplemented with increasing concentrations of either $p$-hydroxybenzalacetone or raspberry ketone dissolved in DMSO using a BioLector microbioreactor. Biomass formation was followed by measuring the backscattered light intensity (gain 10) at a wavelength of $620 \mathrm{~nm}$. The depicted data represent mean values from biological triplicates 


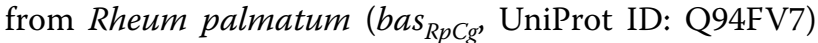
was combined with a gene for different BAR variants. A codon-optimized gene variant of RZS1 $1_{R i}\left(r z s 1_{R i C g}\right.$, UniProt ID: G1FCG0) was used as this particular enzyme has already been successfully applied for the microbial synthesis of RK in E. coli [8]. Previously, cofactor specificity in a RZS1 $1_{R i}$-G191D mutant was reported to be relaxed resulting in the acceptance of NADH as reducing agent [14]. Based on this observation, the same amino acid substitution was also introduced into $r z s 1_{R i C g}$ (rzs$1_{R i C g}$-G191D). Additionally, available scientific data was analyzed to identify endogenous reductases involved in $p$ HBA reduction in E. coli and C. glutamicum. In case of $E$. coli, the NADPH-dependent curcumin/dihydrocurcumin reductase CurA involved in the degradation of this polyphenol (CurA $\mathrm{E}_{E c}$, UniProt ID: P76113) was identified as a promising candidate. Its natural substrate curcumin is a dimer of $p \mathrm{HBA}$ and thus the enzyme might also be active on the monomers (Additional file 1: Figure S1) [20]. Therefore, the native curA gene was amplified from the genome of $E$. coli MG1655 ( $\left.c u r A_{E c}\right)$ but also ordered as codon-optimized variant $\left(c u r A_{E c C g}\right)$ for a possible application in C. glutamicum. To enable IPTG-inducible heterologous gene expression from the strong T7 promotor, the plasmid pMKEx2 was selected [21]. The constructed plasmids were used for the transformation of $C$. glutamicum M-CoA. For evaluation of reductase activity, the generated strains were cultivated for $72 \mathrm{~h}$ in $50 \mathrm{~mL}$ defined CGXII medium with $4 \%$ glucose and $1 \mathrm{mM}$ IPTG supplemented with $500 \mathrm{mg} / \mathrm{L}(3.09 \mathrm{mM}) p$ HBA. Taken samples were extracted with ethyl acetate and analyzed for the synthesis of RK by HPLC (Fig. 3).

Surprisingly, both strains harboring an episomally encoded $r z s 1_{R i C g}$ gene variant did not synthesize more
RK from supplemented $p \mathrm{HBA}$ compared to C. glutamicum M-CoA harboring the empty vector $(12.9 \mathrm{mg} / \mathrm{L}$, $0.08 \mathrm{mM}$ ). This indicates that both $r z s 1_{R i C g}$ variants are not functionally expressed in C. glutamicum. However, in presence of the $\operatorname{curA}_{E \mathcal{C}}, 49.4 \mathrm{mg} / \mathrm{L}(0.3 \mathrm{mM})$ RK were synthesized, indicating not only its functional expression in C. glutamicum but also the capability of $\mathrm{CurA}_{E C}$ to reduce $p$ HBA. When utilizing the codon-optimized $\operatorname{curA} A_{E c C g}$ gene, RK synthesis was increased further to $68.7 \mathrm{mg} / \mathrm{L}$ (0.42 mM). Hence, the pMKEx2-bas ${ }_{R p C g}-c u r A_{E c C g}$ plasmid was selected for all subsequent experiments. Noteworthy, at least one additional reductase conferring $p$ HBA reducing abilities must be present in E. coli, since E. coli BL21 strains, previously also utilized for microbial RK synthesis, do not have the curA gene [1].

\section{Increased NADPH availability improves $p H B A$ reduction}

The observed incomplete conversion of $p \mathrm{HBA}$ to RK suggested intracellular NADPH supply to be a limiting factor during phenylbutanoid synthesis. With the aim to improve $p \mathrm{HBA}$ reduction, previously described strategies for increasing NADPH availability were followed [22]. In particular, elimination of the endogenous lactate dehydrogenase activity, especially in combination with the heterologous expression of the transhydrogenase genes pntAB from $E$. coli, was shown to contribute to increased NADPH availability in C. glutamicum. The constructed strain $C$. glutamicum M-CoA $\Delta l d h A$ was transformed using the plasmid pMKEx2-bas $s_{R p C g}-c u r A_{E-}$ $c C g$. To evaluate, if the deletion of $l d h A$ also increases NADPH availability and thus improves $p$ HBA reduction of C. glutamicum, strains were cultivated both, absence or presence of pMKEx2-bas ${ }_{R p C g}-c u r A_{E c C g}$. Strain cultivation and analysis of taken samples were

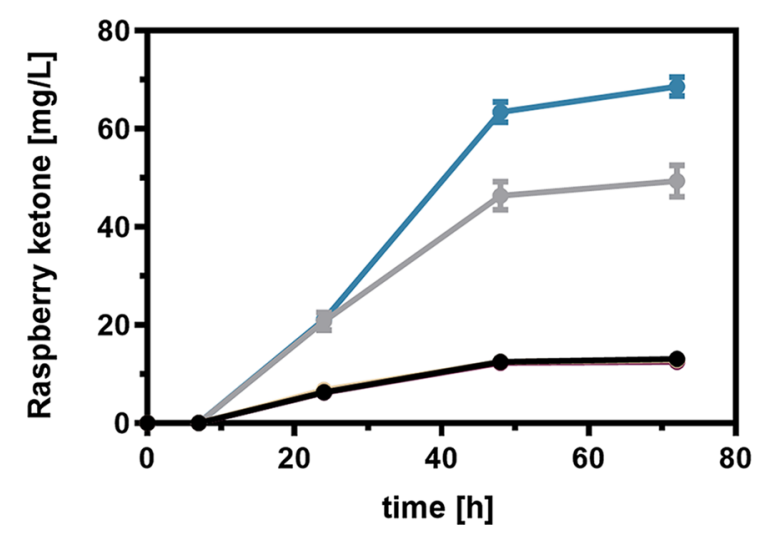

C. glutamicum M-CoA

$\rightarrow$ pMKEx2

pMKEX2-bas ${ }_{R p C g}-r z s 1_{R i c g}$

PMKEX2-bas RpCg $^{-r z s 1_{R i C g}-\text { G191D }}$

pMKEX2-bas $_{R p c g}-c u r A_{E c}$

pMKEx2-bas $_{R p c g}-c u r A_{E c C g}$

Characterization of different heterologous benzalacetone reductases with regard to their suitability for raspberry ketone synthesis using $C$. glutamicum. Different C. glutamicum M-CoA variants harboring one of the indicated expression plasmids were cultivated in $50 \mathrm{~mL}$ CGXII medium with $4 \%$ glucose and $500 \mathrm{mg} / \mathrm{L}$ supplemented $p$-hydroxybenzalacetone in baffled flasks at $30^{\circ} \mathrm{C}$ and $130 \mathrm{rpm}$ for $72 \mathrm{~h}$. The depicted data represent mean values with standard deviations from biological triplicates 
conducted as described above (Additional file 1: Figure S2). Under standard cultivation conditions, sole ldhA deletion did not affect growth, but did also not improve RK synthesis. However, the approach of deleting $l d h A$ was not abandoned although no positive effect on absolute RK titers was observed at this stage. Obviously, limited effects on NADPH-dependent $p \mathrm{HBA}$ reduction generating $\mathrm{RK}$ are not surprising when taking into consideration that the abolished lactate-forming reaction is NADH-dependent, consequently increasing NADH availability. For increasing NADPH supply from $\mathrm{NADH}\left(\mathrm{NADH}+\mathrm{NADP}^{+} \rightarrow \mathrm{NAD}^{+}+\mathrm{NADPH}\right)$, the membrane-bound transhydrogenase PntAB from E. coli (UniProt IDs: P07001 and P0AB67) described earlier was tested [22]. E. coli harbors two transhydrogenase isoforms. Whereas the energy-dependent PntAB enzyme catalyzes the transfer of a hydride ion from NADH to NADP ${ }^{+}$under physiological conditions, the energy-independent cytoplasmatic variant UdhA (UniProt ID: P27306) operates in the reverse direction, when an excess of NADPH is present in the cell [23, 24]. However, in principal, both enzymes are capable of catalyzing both reactions.

The expression plasmids pEKEx3-pntAB $B_{E c}$ and pEKEx3-udh $A_{E c C g}$ either harboring the native pntAB genes from E. coli (pntAB $B_{E c}$ ) or a codon-optimized $u d h A$ variant $\left(u d h A_{E c C g}\right)$, each under control of the tac promoter, were constructed. Subsequently, these plasmids were used for transformation of C. glutamicum M-CoA $\triangle l d h A$ harboring pMKEx2-bas $s_{R p C g}-c u r A_{E c C g}$. The resulting strains were cultivated under the same conditions as described before. As heterologous expression of genes encoding for integral membrane proteins often cause growth defects, multiple IPTG concentrations ranging from 10 to $1000 \mu \mathrm{M}$ were tested for the heterologous expression of pntAB $E c$. These experiments showed that an increasing IPTG concentration was always associated with an increasing growth defect up to a complete arrest of growth (Additional file 1: Figure S3). HPLC analysis indicated a drastically impaired RK synthesis for all IPTG concentrations compared to the reference strain with $1 \mathrm{mM}$ IPTG, rendering the heterologous expression of pntAB unsuitable for RK synthesis in C. glutamicum.

Contrary, episomal expression of $u d h A_{E c C g}$ barely affected microbial growth but increased RK titers up to $25 \%$ (Additional file 1: Figure S4). This indicates that the functional expression of $u d h A_{E c C g}$ in C. glutamicum allows for the hydride ion transfer from $\mathrm{NADH}$ to $\mathrm{NADP}^{+}$. Interestingly, functional expression of udhA from E. coli in C. glutamicum has already been demonstrated earlier, though utilized for the opposite hydride ion transfer [25]. Thus, C. glutamicum M-CoA $\Delta l d h A$ harboring the two expression plasmids
pMKEx2-bas $s_{R p C g}-c u r A_{E c C g}$ and pEKEx3-udh $A_{E c C g}$ provides the highest BAR activity, resembling a promising candidate for establishing (4CL and) BAS activity to complete the heterologous pathway for RK synthesis from supplemented $p$ CA.

\section{Raspberry ketone synthesis from $p$-coumaric acid}

So far, RK synthesis in C. glutamicum was only achieved by supplementation of the diketide intermediate $p$ HBA. As C. glutamicum M-CoA provides increased amounts of malonyl-CoA, synthesis of $p \mathrm{HBA}$ from $p \mathrm{CA}$ should be also possible. In addition to BAS from Chinese rhubarb (R. palmatum), which was shown to feature a novel catalytic mechanism allowing for the sole synthesis of $p \mathrm{HBA}$, the bifunctional chalcone synthases PKS1 (UniProt ID: Q9AU11) and PKS4 (UniProt ID: B0LDU5) from raspberry ( $R$. idaeus) were tested for $p$ HBA synthesis from supplemented $p C A$ in C. glutamicum [26-29]. Both enzymes were described to have a BAS side activity in addition to their CHS activity. Codon-optimized gene variants $p k s 1_{R i C g}$ and $p k s 4_{R i C g}$ were used to con-

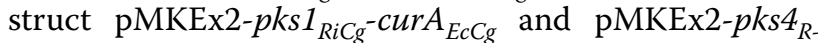
${ }_{r C g} g^{-c u r A} A_{E c C g}$. For evaluation of (4CL and) BAS activity, the constructed strains were cultivated and analyzed as described above with supplementation of $5 \mathrm{mM} p C A$ instead of $3.09 \mathrm{mM}$ pHBA. Stacked concentrations of $p \mathrm{HBA}$ and $\mathrm{RK}$ were used to assess the (4CL and) BAS activity (Fig. 4).

Utilization of the already applied bas gene from $R$. palmatum enabled RK synthesis from $p$ CA in C. glutamicum. After $72 \mathrm{~h}$ of cultivation in the absence of $u d h A_{E c C g}, 14 \mathrm{mg} / \mathrm{L}(0.09 \mathrm{mM}) \mathrm{RK}$ and $9.4 \mathrm{mg} / \mathrm{L}$ $(0.06 \mathrm{mM}) p \mathrm{HBA}$ were detected by HPLC. In contrast to the previous experiments, $u d h A_{E c C g}$ expression reduced $p \mathrm{HBA}$ - and RK synthesis. In addition, neither expression of $p k s 1$ nor $p k s 4$ in combination with curA enabled RK synthesis, suggesting that both genes were not functionally expressed in C. glutamicum. Since both enzymes are primarily chalcone synthases, it was also tested whether naringenin chalcone, or more precisely, naringenin was formed. However, also no detectable amounts of naringenin were synthesized, indicating that PKS1 and PKS4 might be incorrectly folded in C. glutamicum. Previously, $\mathrm{N}$-terminal translational fusion with the maltose binding protein from E. coli $\left(\mathrm{MalE}_{E c}\right)$ was demonstrated to efficiently increase functional expression of heterologous plant genes in C. glutamicum [30]. To test whether functional expression of $p k s$ genes could be achieved by mimicking this strategy, C. glutamicum strains harboring the plasmids pMKEx2-malE $E_{E c}-p k s 1_{R i C g}-c u r A_{E c C g}$ and pMKEx2-malE $E_{E c}-p k s 4_{R i C g}-c u r A_{E c C g}$ were constructed and cultivated. Although, general applicability of this strategy was indicated by the formation of RK when expressing 

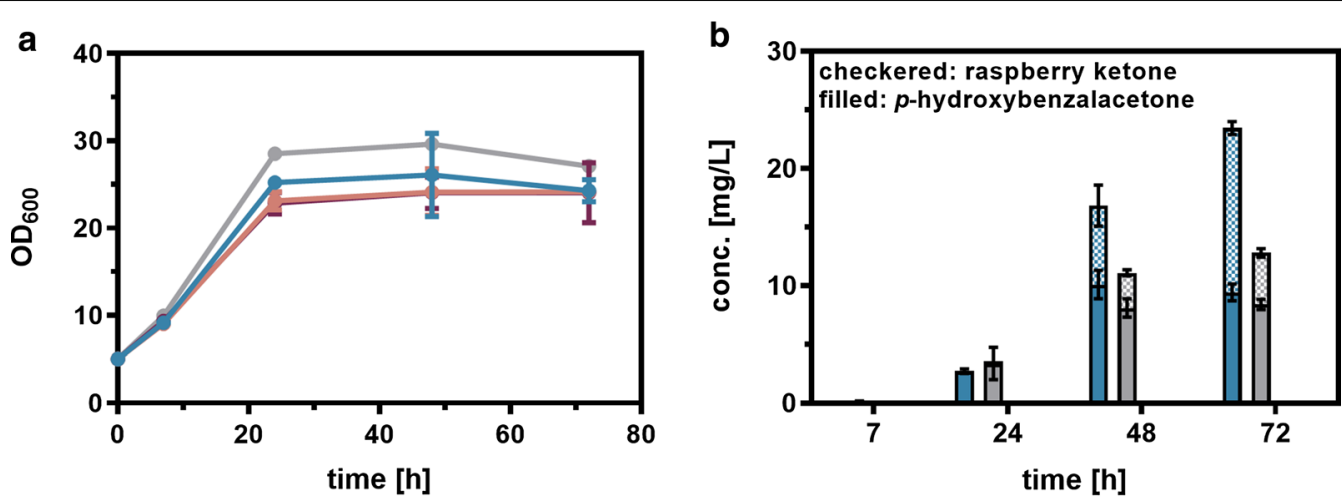

C. glutamicum M-CoA $\triangle / d h A$

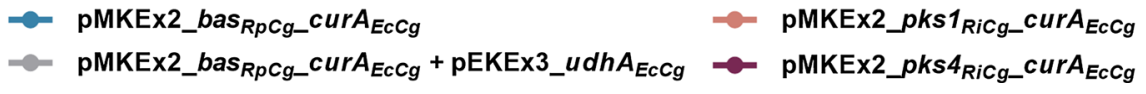

Fig. 4 Evaluation of different benzalacetone synthases for raspberry ketone production from $p$-coumaric acid using C. glutamicum. C. glutamicum $\mathrm{M}$-COA $\triangle / d h A$ harboring the indicated expression plasmids was cultivated in $50 \mathrm{~mL} C G X I I$ medium with $4 \%$ glucose and $5 \mathrm{mM} p$-coumaric acid in baffled flasks at $30^{\circ} \mathrm{C}$ and $130 \mathrm{rpm}$ for $72 \mathrm{~h}$. $\mathbf{a}$ Growth and $\mathbf{b} p$-hydroxybenzalacetone- and raspberry ketone synthesis was followed over time. Determined concentrations for $p$-hydroxybenzalacetone and raspberry ketone in cell extracts were stacked for a better visualization. The depicted data represent mean values with standard deviations from biological triplicates

$m a l E_{E c}-p k s 1_{R i C g}$ and $m a l E_{E c}-p k s 4_{R i C g}$, significantly less RK was formed in comparison to $\mathrm{BAS}_{R p}$.

Taken together, C. glutamicum M-CoA $\Delta l d h A$ harboring pMKEx2-bas ${ }_{R p C g}-c u r A_{E c C g}$ and pEKEx3-udhA $A_{E c C g}$ is regarded as the most suitable strain for the synthesis of RK from supplemented diketide intermediate $p \mathrm{HBA}$, whereas additional $u d h A_{E c C g}$ expression was not beneficial for the synthesis from $p \mathrm{CA}$.

\section{Microbial synthesis of zingerone and benzylacetone}

Besides RK, other phenylbutanoids such as the ferulic acid-derived zingerone or the cinnamic acid-derived benzylacetone are of commercial interest as well. Zingerone is regarded as the molecule providing the characteristic flavor of cooked ginger, whereas benzylacetone is described to contribute to the characteristic taste of strawberries and jasmine [31-34]. The respective molecules differ from RK only in their hydroxylation/methoxylation pattern of the aromatic ring (Fig. 1). Thus, it is reasonable to assume that the enzymes of the RK pathway also accept ferulic acid and cinnamic acid (and their derivatives) as substrates, which would offer the opportunity for a combinatorial biosynthesis of zingerone or benzylacetone using the very same C. glutamicum strain (Fig. 1). First, confirmation of reductase activity with the respective diketide intermediates of zingerone and benzylacetone synthesis was addressed as formation of the diketide $p \mathrm{HBA}$ from $p \mathrm{CA}$ by $4 \mathrm{CL}_{P c}$ and $\mathrm{BAS}_{R p}$ was rather inefficient and might be even more challenging with alternative phenylpropanoids as substrates. To this end, CGXII medium was supplemented with the respective diketide precursors (3.09 $\mathrm{mM}$ ) during cultivations of C. glutamicum M-CoA $\triangle l d h A$, optionally harboring pMKEx2bas $_{R p C g}$-cur $A_{E c C g}$. HPLC analysis of extracted samples demonstrated synthesis of $40.2 \mathrm{mg} / \mathrm{L}(0.21 \mathrm{mM})$ zingerone upon $c u r A_{E c C g}$ expression whereas the synthesis of benzylacetone was unaffected $(0.6 \mathrm{mg} / \mathrm{L}, 0.01 \mathrm{mM})$ indicating that $\mathrm{CurA}_{E c C g}$ cannot reduce benzalacetone (Additional file 1: Figure S5). Therefore, benzalacetone appears to be solely reduced by the unknown endogenous reductase activity of $C$. glutamicum yielding benzylacetone. Interestingly, less zingerone $(70 \mathrm{mg} / \mathrm{L}$, $0.36 \mathrm{mM})$ compared to RK $(99.8 \mathrm{mg} / \mathrm{L}, 0.61 \mathrm{mM})$ was produced from the respective diketide intermediate despite an even higher similarity to the curcumin structure (Fig. 5b).

Nevertheless, reductase activity of the constructed strain C. glutamicum M-CoA $\Delta l d h A$ carrying pMKEx2bas $_{R p C g}-c u r A_{E c C g}$ and pEKEx3-udhA $A_{E c C g}$ was verified for all tested substitution patterns of the aromatic ring.

To evaluate substrate promiscuity of the diketide forming enzymes $4 \mathrm{CL}_{P c}$ and $\mathrm{BAS}_{R p}$, C. glutamicum M-CoA $\triangle l d h A$ harboring pMKEx2-bas ${ }_{R p C g}-c u r A_{E c C g}$ and pEKEx3-udhA $A_{E c C g}$ was cultivated using standard conditions with supplementation of the respective phenylpropanoids $(5 \mathrm{mM})$. Extracted samples were analyzed by HPLC for the presence of respective diketides and ketones (Fig. 5d). After $72 \mathrm{~h}$ of cultivation, $7.9 \mathrm{mg} / \mathrm{L}(0.05 \mathrm{mM}) \mathrm{pHBA}$ and $4.7 \mathrm{mg} / \mathrm{L}$ (0.05 mM) RK 

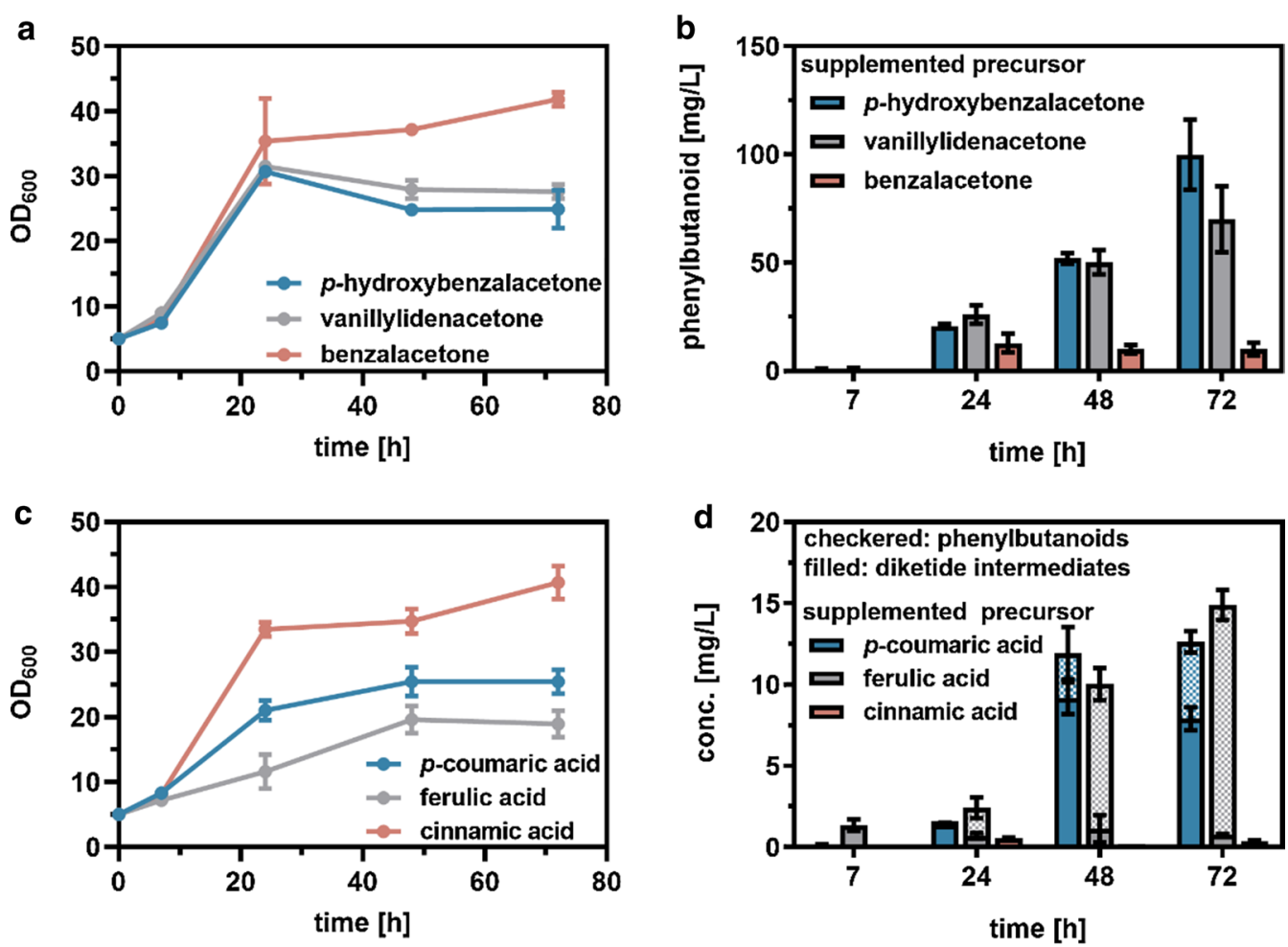

Fig. 5 Combinatorial biosynthesis of phenylbutanoids zingerone and benzylacetone from supplemented phenylpropanoid-and diketide precursors using C. glutamicum M-CoA $\triangle / d h A$ pMKEx2-bas RpCg $^{-C U R A_{E C C g}}$ PEKEX3-udhA $A_{E C C g}$. Cultivations were performed in $50 \mathrm{~mL}$ CGXII medium with $4 \%$ glucose and either $3.09 \mathrm{mM}$ diketide or $5 \mathrm{mM}$ phenylpropanoid precursors in baffled flasks at $30^{\circ} \mathrm{C}$ and $130 \mathrm{rpm}$ for $72 \mathrm{~h}$. Here, supplementation of $p$-coumaric acid and $p$-hydroxybenzalacetone for the synthesis of RK served as a positive control. a Microbial growth and $\mathbf{b}$ phenylbutanoid synthesis from supplemented diketides. c Microbial growth and $\mathbf{d}$ phenylbutanoid synthesis from supplemented phenylpropanoids. Where appropriate, determined concentrations for diketides (filled bars) and phenylbutanoids (checkered bars) were stacked for a better data visualization. Depicted data represent mean values with standard deviations from biological triplicates

were formed from $p C A$. When supplementing either ferulic acid or cinnamic acid, $0.8 \mathrm{mg} / \mathrm{L}(0.01 \mathrm{mM})$ vanillylidenacetone and $14.1 \mathrm{mg} / \mathrm{L}(0.07 \mathrm{mM})$ zingerone or $0.4 \mathrm{mg} / \mathrm{L}(0.01 \mathrm{mM})$ benzalacetone but no detectable benzylacetone was formed, respectively.

In principle, the precursors and intermediates of zingerone and benzylacetone synthesis can be converted also by the heterologous pathway for RK synthesis established in C. glutamicum. Nevertheless, benzylacetone could not be produced from cinnamic acid, probably due to the insufficient synthesis of the diketide intermediate benzalacetone. Contrary to previous results obtained from cultivations with supplemented diketide intermediates, the reduction of vanillylidenacetone appears to be more efficient compared to $p \mathrm{HBA}$ reduction, as almost all vanillylidenacetone synthesized was converted to zingerone.

\section{Discussion}

In this study, we constructed a C. glutamicum variant for the microbial synthesis of the flavoring phenylbutanoids RK, zingerone and benzylacetone. Initial cytotoxicity experiments of $p \mathrm{HBA}$ and RK suggested $C$. glutamicum to be more resistant to these compounds compared to E. coli and S. cerevisiae. For the latter two microorganisms, half maximal inhibitory concentrations $\left(\mathrm{IC}_{50}\right)$ have been calculated for both $S$. cerevisiae and $E$. coli [1]. Here, concentrations of $100 \mathrm{mg} / \mathrm{L}$ or $300 \mathrm{mg} / \mathrm{L} p \mathrm{HBA}$ and $500 \mathrm{mg} / \mathrm{L}$ or $900 \mathrm{mg} / \mathrm{L}$ were determined for $S$. cerevisiae and E. coli to reduce biomass formation by $50 \%$, respectively. Since the calculation of $\mathrm{IC}_{50}$ values for $C$. glutamicum would be imprecise due to insufficient data for higher concentrations of both molecules, we cannot provide exact concentrations. Nevertheless, the cytotoxicity experiments allow to consider C. glutamicum to be more resistant to both $p \mathrm{HBA}$ and $\mathrm{RK}$ as the $\mathrm{IC}_{50}$ concentrations have to be $>500 \mathrm{mg} / \mathrm{L}$ and $>1000 \mathrm{mg} / \mathrm{L}$, respectively. More importantly, the constructed strain C. glutamicum M-CoA $\triangle l d h A$ pMKEx2-bas $s_{R p C g}-c u r A_{E c C g}$ accumulates up to $14 \mathrm{mg} / \mathrm{L}(0.09 \mathrm{mM}) \mathrm{RK}$ from supplemented $p \mathrm{CA}$, which is comparable to the product titer determined for a $S$. cerevisiae strain $(7.5 \mathrm{mg} / \mathrm{L} \mathrm{RK}(0.05 \mathrm{mM}))$ [13]. 
However, synthesis of $91 \mathrm{mg} / \mathrm{L}(0.55 \mathrm{mM})$ RK from $p C A$ using an engineered $E$. coli BL21(DE3) variant was recently reported [8].

Moreover, a yet unknown substrate promiscuity of the NADPH-dependent curcumin/dihydrocurcumin reductase CurA from E. coli MG1655 allowing for the efficient reduction of $p \mathrm{HBA}$ and vanillylidenacetone, respectively, was identified. Although E. coli BL21 has been previously reported to possess an endogenous BAR activity, this activity presumably cannot be traced back to CurA as this particular gene is not present in the utilized strain background [1]. Thus, it is likely that at least one additional reductase also features BAR activity in $E$. coli BL21. We presumed a possible enzymatic activity of CurA with $p \mathrm{HBA}$ due to structural similarities with its natural substrate curcumin (Additional file 1: Figure S1). As the additional methoxy group of vanillylidenacetone increases structural similarity to curcumin even more, a more efficient conversion to the corresponding ketone compared to the RK branch was expected prior to the conducted experiments. Indeed, when producing flavoring phenylbutanoids from supplemented phenylpropanoids, an almost complete conversion of vanillylidenacetone to zingerone was observed, whereas $p \mathrm{HBA}$ reduction was less efficient.

Furthermore, a hitherto unknown endogenous BAR activity must be also present in C. glutamicum as demonstrated by the reduction of the three tested diketide intermediates in the absence of $c u r A_{E c C g}$. Apart from $E$. coli and C. glutamicum, such an activity has already been described for S. cerevisiae [13].

To increase NADPH supply for the efficient reduction of diketide intermediates, heterologous expression of genes encoding the membrane-bound as well as the cytoplasmatic transhydrogenases from $E$. coli was evaluated. Despite already being used to increase NADPH availability in an isobutanol producing C. glutamicum variant, the membrane-bound transhydrogenase PntAB turned out to be unsuitable for RK synthesis with the same bacterium [22]. With increasing induction strength, a severe growth defect in C. glutamicum was observed upon pntAB expression. This might indicate cytotoxic effects of the transhydrogenase itself, but also the absence of chaperones supporting folding or an altered membrane composition could be the cause [35]. Contrary, the cytoplasmatic transhydrogenase UdhA was beneficial for RK synthesis resembling a promising alternative to the membrane-bound PntAB. Despite being rather involved in the energy-independent hydride ion transfer from NADPH to $\mathrm{NAD}^{+}$in vivo, UdhA can still catalyze the transfer in the reverse direction [23]. Nevertheless, the equilibrium of the transhydrogenation reaction could be shifted towards NADPH, when NADPH is constantly withdrawn by the reduction of $p \mathrm{HBA}$ to RK. Furthermore, deletion of $l d h A$ increases NADH availability, which in turn also shifts the equilibrium of the transhydrogenase reaction towards NADPH. Further strategies for increased $\mathrm{NADPH}$ supply in C. glutamicum involve altering the coenzyme specificity of the $\mathrm{NAD}^{+}$-dependent glyceraldehyde 3-phophate dehydrogenase (GAPDH) to NADP ${ }^{+}$, which was done in the context of L-lysine production with C. glutamicum [36]. It should be noted, that an imbalanced NADH/NADPH distribution could perturb the cellular metabolism and might even inhibit cellular growth or glucose consumption [36].

Interestingly, expression of $u d h A_{E c C g}$ appears to be disadvantageous for the synthesis of $p \mathrm{HBA}$ and RK from $p C A$. NADPH availability could not be limiting for the small amounts of $p \mathrm{HBA}$ produced from $p \mathrm{CA}$, so that the described positive effect of additional NADPH supply only become significant at higher $p \mathrm{HBA}$ concentrations. The reduced cumulated titer of $p \mathrm{HBA}$ and RK might be due to the increased metabolic burden of the cell due to maintenance of the pEKEx3-udh $A_{E c C g}$ plasmid (requiring supplementation of a second antibiotic and expression of an additional antibiotic resistance gene) [37, 38].

\section{Conclusion}

In the present work, we extended the product portfolio of C. glutamicum towards flavoring phenylbutanoids. We identified an endogenous BAR activity of C. glutamicum and a yet unknown substrate promiscuity of CurA from $E$. coli that turned out to be a promising BAR. Moreover, the cytoplasmatic transhydrogenase UdhA from $E$. coli allowed for increased NADPH supply and ultimately improved RK synthesis. Taken together, the constructed strain C. glutamicum M-CoA $\triangle l d h A$ harboring pMKEx2bas $_{R p C g}-c u r A_{E c C g}$ and pEKEx3-udhA $A_{E c C g}$ represents a versatile host for the synthesis of up to $99.8 \mathrm{mg} / \mathrm{L}(0.61 \mathrm{mM})$ $\mathrm{RK}, 70 \mathrm{mg} / \mathrm{L}(0.36 \mathrm{mM})$ zingerone and $10.5 \mathrm{mg} / \mathrm{L}$ (0.07 $\mathrm{mM})$ benzylacetone.

\section{Materials and methods}

Bacterial strains, plasmids, media and growth conditions

All bacterial strains and plasmids with their respective characteristics used in this study are listed in Table 1. C. glutamicum strains were routinely cultivated aerobically at $30{ }^{\circ} \mathrm{C}$ in brain heart infusion (BHI) medium (Difco Laboratories, Detroit, USA) or defined CGXII medium with $4 \%(\mathrm{w} / \mathrm{v})$ glucose as sole carbon and energy source [39]. E. coli DH5 $\alpha$, used solely for plasmid constructions, was cultivated in LB medium at $37^{\circ} \mathrm{C}$ [40]. Where appropriate, kanamycin (E. coli $50 \mu \mathrm{g} / \mathrm{mL}$, C. glutamicum $25 \mu \mathrm{g} / \mathrm{mL})$ and/or spectinomycin $(100 \mu \mathrm{g} / \mathrm{mL}$ for $E$. coli and C. glutamicum) was added to the respective medium. 
Table 1 Strains and plasmids used in this study

\begin{tabular}{|c|c|c|}
\hline Strain or plasmid & Characteristics & Source \\
\hline \multicolumn{3}{|l|}{ C. glutamicum strains } \\
\hline $\begin{array}{l}\text { DelAro }^{4}-4 C l_{P C} C 5 \text { mufasO }_{B C D 1} \\
P_{\mathrm{O}_{6}}-10 / T 1 \triangle p y C(\mathrm{M}-\mathrm{COA})\end{array}$ & $\begin{array}{l}\text { C. glutamicum derivative with in-frame deletions of cg0344-47, cg0503 cg2625-40 and cg1226; } \\
\text { harboring a chromosomally encoded codon-optimized } 4 C l_{p c} \text { gene coding for 4-coumarate:CoA } \\
\text { ligase from P. crispum under control of the T7 promoter and replacement of the native gltA pro- } \\
\text { motor with the dapA promotor variant } C 5 \text {, mutated fas } O \text { binding sites upstream of } a c c B C \text { and } \\
\text { accD1, two nucleotide exchanges in the iolT1 promotor and in-frame deletion of pyc }\end{array}$ & [16] \\
\hline $\mathrm{M}-\mathrm{COA} \triangle \mathrm{dh} A$ & C. glutamicum M-CoA derivative with in-frame deletion of IdhA & This work \\
\hline \multicolumn{3}{|l|}{ E. coli strains } \\
\hline $\mathrm{DH} 5 \mathrm{a}$ & $\mathrm{F}^{-}$Ф80lacZDM15 $\triangle$ (lacZYA-argF)U169 recA1 endA1 hsdR17 $\left(\mathrm{r}_{\mathrm{K}}^{-}, \mathrm{m}_{\mathrm{K}}^{+}\right)$phoA supE44 $\lambda^{-}$thi-1 gyrA96 relA1 & $\begin{array}{l}\text { Invitrogen } \\
\text { (Karlsruhe, } \\
\text { Germany) }\end{array}$ \\
\hline \multicolumn{3}{|l|}{ Plasmids } \\
\hline pK19mobsacB- $\triangle / d h A$ & Vector for in-frame deletion of IdhA & [46] \\
\hline pMKEX2 & 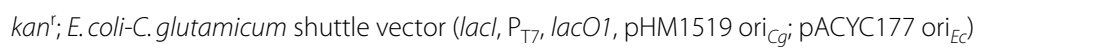 & [21] \\
\hline pMKEX2-bas ${ }_{R p C g}-r Z s 1_{R i C g}$ & 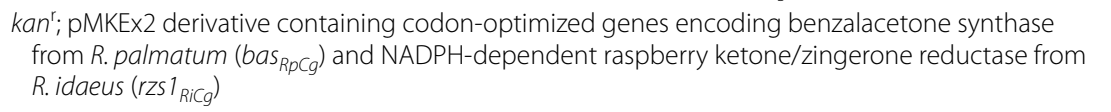 & This work \\
\hline pMKEx2-bas RpCg $^{-r Z S} 1_{\text {Ricg }}-\mathrm{G} 191 \mathrm{D}$ & $\begin{array}{l}\text { kan }^{r} \text {; pMKEX2-bas } \\
\text { to amino acid substitution G191D in RZS1 } 1_{R i} \text {. }\end{array}$ & This work \\
\hline pMKEX2-bas ${ }_{R p C g}-$ CurA $A_{E C}$ & 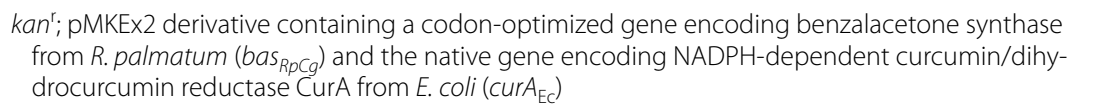 & This work \\
\hline pMKEx2-bas ${ }_{R p C g}-$ CurA $A_{E C C g}$ & 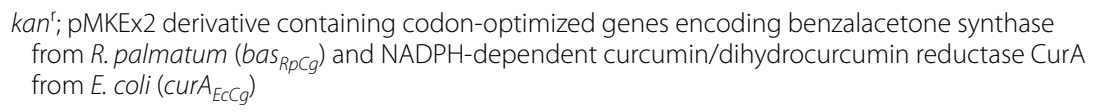 & This work \\
\hline pMKEX2-pks $1_{R i C g}-C U r A_{E C C g}$ & 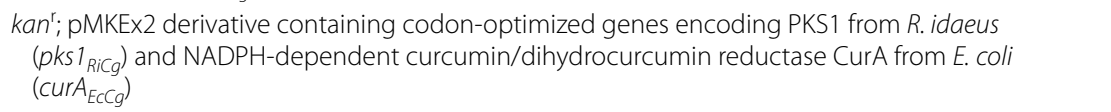 & This work \\
\hline pMKEX2-pks $4_{\text {Ric }}-C U r A_{E C C g}$ & 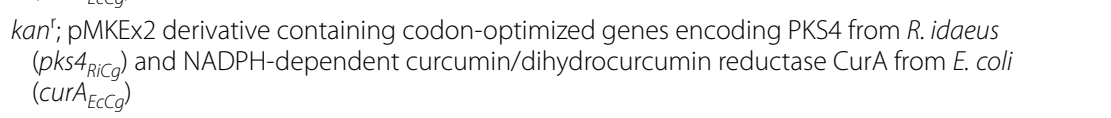 & This work \\
\hline pMKEX2-malE $E_{E C}-p k s 1_{R i C g}-C u r A_{E C C g}$ & $\begin{array}{l}\text { kan }^{r} \text {; pMKEx2 derivative containing the native malE gene from E. coli fused to the codon-opti- } \\
\text { mized gene encoding PKS1 from R. idaeus (malE } E_{E C}-p k s 1_{R i c g} \text { ) and a codon-optimized gene encod- } \\
\text { ing NADPH-dependent curcumin/dihydrocurcumin reductase CurA from E. coli }\left(c u r A_{E C C g}\right)\end{array}$ & This work \\
\hline pMKEx2-malE $E_{E C}-p k s 4_{R i C g}-C u r A_{E C C g}$ & $\begin{array}{l}\text { Kan }^{r} \text {; pMKEx2 derivative containing the native malE gene from E. coli fused to the codon-opti- } \\
\left.\text { mized gene encoding PKS4 from R. idaeus (malE } E_{E C}-p k s A_{R i C g}\right) \text { and a codon-optimized gene encod- } \\
\text { ing NADPH-dependent curcumin/dihydrocurcumin reductase CurA from E. coli }\left(C u r A_{E C C g}\right)\end{array}$ & This work \\
\hline pEKEX3 & 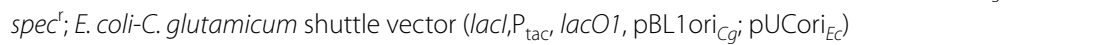 & [47] \\
\hline pEKEx3-pntAB $B_{E C}$ & $\begin{array}{l}\text { spec'; p } \mathrm{EKEX} 3 \text { derivative containing native pntAB genes from } E \text {. coli ( } p n t A B_{E C} \text { ) encoding a mem- } \\
\text { brane-bound transhydrogenase }\end{array}$ & This work \\
\hline pEKEx3-udhA $A_{E C C g}$ & $\begin{array}{l}\left.\text { spec'; p pEKEx3 derivative containing codon-optimized udhA gene variant from E. coli ( } u d h A_{E C C g}\right) \\
\text { encoding a cytoplasmatic transhydrogenase }\end{array}$ & This work \\
\hline pEKEx3-malE $E_{E C}-o m t_{V V}$ & $\begin{array}{l}\text { spec'; pEKEx3 derivative containing malE gene from } E \text {. coli }\left(\text { mal } E_{E C}\right) \text { fused to the codon-optimized } \\
\text { gene coding for resveratrol-di-O-methyltransferase from } V \text {. vinifera }\left(o m t_{V V}\right)\end{array}$ & {$[30]$} \\
\hline
\end{tabular}

Bacterial growth was followed by measuring the optical density at $600 \mathrm{~nm}\left(\mathrm{OD}_{600}\right)$.

To cultivate $C$. glutamicum, a test tube with $5 \mathrm{~mL}$ BHI medium was inoculated with a single colony from an agar plate and grown for $6-8 \mathrm{~h}$ on a rotary shaker at $170 \mathrm{rpm}$ (first preculture). This first preculture was used to inoculate $50 \mathrm{~mL}$ of defined CGXII medium with $4 \%(\mathrm{w} / \mathrm{v})$ glucose in a $500 \mathrm{~mL}$ baffled Erlenmeyer flask (second preculture). The second preculture was cultivated overnight on a rotary shaker at $130 \mathrm{rpm}$. The main culture was subsequently inoculated from the second preculture to the indicated $\mathrm{OD}_{600}$ in defined CGXII medium with $4 \%(\mathrm{w} / \mathrm{v})$ glucose. For microbial synthesis of phenylbutanoids, the main culture was inoculated to an $\mathrm{OD}_{600}$ of 5 in defined CGXII medium with $4 \%$ glucose and heterologous gene expression was induced 90 min after inoculation using $1 \mathrm{mM}$ IPTG. $1 \mathrm{~mL}$ of the culture broth was sampled at 
defined time points and stored at $-20{ }^{\circ} \mathrm{C}$ until ethyl acetate extraction and HPLC analysis.

For evaluating cytotoxicity of $p \mathrm{HBA}$ and RK, C. glutamicum M-CoA was cultivated at $30{ }^{\circ} \mathrm{C}, 900 \mathrm{rpm}$ and a humidity of $85 \%$ in 48 -well Flowerplates containing 800 $\mu \mathrm{L}$ CGXII medium with $4 \%(\mathrm{w} / \mathrm{v})$ glucose inoculated to an $\mathrm{OD}_{600}$ of 1 , using the BioLector microbioreactor (m2p-labs, Baesweiler, Germany). Increasing concentrations of both $p \mathrm{HBA}$ and RK (final concentrations 0, $15.625,31.25,62.5,125,250,500$ and $1000 \mathrm{mg} / \mathrm{L}$ ), dissolved in $10 \mu \mathrm{L}$ DMSO were added. Online measurement of the backscattered light intensity $(620 \mathrm{~nm}$, gain 10) was used for evaluation of cellular growth. To estimate $\mathrm{IC}_{50}$ values, obtained backscattered light intensities after $72 \mathrm{~h}$ were plotted against the respective $p \mathrm{HBA}$ - and RK concentrations and subsequently analyzed using the GraphPad Prism 8.1.2 software (San Diego, CA, USA). The nonlinear regression [inhibitor] vs. response - Variable slope (four parameters) with the following specifications was used: top $=165$, bottom $=15$, as well as $\mathrm{IC}_{50}>0$. The values for top and bottom correspond to the mean values for the determined backscatter values after $72 \mathrm{~h}$ in the absence of $p \mathrm{HBA}$ or $\mathrm{RK}$, or the average value for the backscatter after $72 \mathrm{~h}$ in the presence of $1000 \mathrm{mg} / \mathrm{L}$ (6.17 mM) $p \mathrm{HBA}$.

\section{Plasmid and strain construction}

Standard protocols of molecular cloning, such as PCR, restriction and ligation of DNA were carried out for recombinant DNA work [41]. All enzymes were obtained from Thermo Fisher Scientific (Schwerte, Germany). Codon-optimized synthetic genes for C. glutamicum ATCC13032 were obtained from Thermo Fisher Scientific (formerly GeneArt, Darmstadt, Germany). Genes and chromosomal fragments were amplified by PCR from synthetic genes or genomic E. coli DNA as template using the listed oligonucleotides (Additional file 1: Table S1). PCR products were subsequently used to clone genes and genomic fragments into plasmid vectors using Gibson assembly [42]. In-frame gene deletions in the C. glutamicum genome were performed using the pK19mobsacB system by a two-step homologous recombination method described previously $[43,44]$. Integrity of all constructed plasmids was verified by colony PCR, restriction analysis, and DNA sequencing at Eurofins MWG Operon (Ebersberg, Germany) Techniques specific for C. glutamicum, e.g. electroporation of cells, were performed as described previously [45].

\section{Ethyl acetate extraction and HPLC quantification}

Phenylbutanoids and pathway intermediates were extracted from cultivation broth for subsequent HPLC analysis by mixing $1 \mathrm{~mL}$ of the culture broth with $1 \mathrm{~mL}$ ethyl acetate and vigorous shaking $(1400 \mathrm{rpm}, 10 \mathrm{~min}$, $20{ }^{\circ} \mathrm{C}$ ) in a Thermomixer (Eppendorf, Hamburg, Germany). The suspension was centrifuged for $5 \mathrm{~min}$ at $13,000 \mathrm{rpm}$ and the upper ethyl acetate layer $(800 \mu \mathrm{L})$ was transferred to an organic solvent resistant deepwell plate (Eppendorf, Hamburg, Germany). After evaporation to dryness, extracts were resuspended in the same volume of acetonitrile and subsequently used for HPLC analysis.

Metabolites were quantified using an Agilent high-performance liquid chromatography (HPLC) 1260 Infinity System equipped with a 1260 Infinity DAD (Agilent Technologies, Waldbronn, Germany). Authentic standards of benzalacetone, benzylacetone, cinnamic acid, ferulic acid, $p$-coumaric acid, vanillylidenacetone and zingerone were purchased from Sigma-Aldrich (Taufkirchen, Germany), $p$-hydroxybenzalacetone was obtained from Alfa Aesar (Kandel, Germany) and raspberry ketone from Acros Organics (Geel, Belgium). LC separation was carried out with an InfinityLab Poroshell $1202.7 \mu \mathrm{m} \mathrm{EC-C_{18 }}$ column $(3.0 \times 150 \mathrm{~mm}$; Agilent Technologies, Waldbronn, Germany) at $50{ }^{\circ} \mathrm{C}$. For elution, $0.1 \%$ acetic acid (solvent $\mathrm{A}$ ) and acetonitrile supplemented with $0.1 \%$ acetic acid (solvent B) were applied as the mobile phases at a flow rate of $0.7 \mathrm{~mL} / \mathrm{min}$. Depending on the analyte, a different elution gradient was used, where the amount of solvent B was increased stepwise. Raspberry ketone: minute 0-10: $10 \%$, minute 10-11: $10-90 \%$, minute 11-13: $90 \%$, minute $13-15$ : $90-10 \%$ and minute $15-17$ : $10 \%$. Absorption was determined at $275 \mathrm{~nm}$ (raspberry ketone), $310 \mathrm{~nm}$ (p-coumaric acid) and $320 \mathrm{~nm}$ (p-hydroxybenzalacetone). Zingerone: minute 0-15: 10\%, minute 15-16: 10-90\%, minute 16-18: 90\%, minute $18-20$ : $90-10 \%$ and minute $20-22$ : $10 \%$. Absorption was determined at $275 \mathrm{~nm}$ (zingerone) and $320 \mathrm{~nm}$ (ferulic acid and vanillylidenacetone). Benzylacetone: minute 0-13: 10-50\%, minute 13-15: 50\%, minute 15-17: $50-10 \%$ and minute 17-19: 10\%. Absorption was determined at $260 \mathrm{~nm}$ (benzylacetone) and $320 \mathrm{~nm}$ (cinnamic acid and benzalacetone). Area values of integrated signals were linear up to metabolite concentrations of at least $83.3 \mathrm{mg} / \mathrm{L}$. 


\section{Supplementary information}

Supplementary information accompanies this paper at https://doi. org/10.1186/s12934-020-01351-y.

Additional file 1. Additional information containing a list of oligonucleotides used in this study, the chemical structure of curcumin with highlighted $p$ HBA structure and additional cultivation results.

\section{Acknowledgements}

Not applicable.

\section{Authors' contributions}

LM and MM conceived the design of this study. LM and MM performed the experimental work. LM and JM wrote the manuscript. All authors read and approved the final manuscript.

\section{Funding}

This work was funded by the Bioeconomy Science Center (BioSC) as part of the FocusLab project "HylmPAct-Hybrid processes for important precursor and active pharmaceutical ingredients" (Grant No.: 325 - 400002 13) and by the German Federal Ministry of Education and Research (BMBF, Grant No.: 031B0918A) as part of the project "BioökonomieREVIER".

\section{Availability of data and materials}

All data generated or analyzed during this study are included in this published article and its additional files.

\section{Ethics approval and consent to participate}

Not applicable.

\section{Consent for publication}

Not applicable.

\section{Competing interests}

The authors declare that they have no competing interests.

\author{
Author details \\ ${ }^{1}$ Institute of Bio- and Geosciences, IBG-1: Biotechnology, Forschungszen- \\ trum Jülich $\mathrm{GmbH}, 52425$ Jülich, Germany. ${ }^{2}$ Bioeconomy Science Cente \\ (BioSC), Forschungszentrum Jülich GmbH, 52425 Jülich, Germany. ${ }^{3}$ Institute \\ of Biotechnology, RWTH Aachen University, Worringer Weg 3, 52074 Aachen, \\ Germany.
}

Received: 4 February 2020 Accepted: 13 April 2020

Published online: 21 April 2020

\section{References}

1. Beekwilder J, Van der Meer IM, Sibbbesen O, Broekgaarden M, Qvist I, Mikkelsen JD, et al. Microbial production of natural raspberry ketone. Biotechnol J. 2007:2:1270-9. https://doi.org/10.1002/biot.200700076.

2. Bredsdorff L, Wedebye EB, Nikolov NG, Hallas-Møller T, Pilegaard K. Raspberry ketone in food supplements - high intake, few toxicity data-a cause for safety concern? Regul Toxicol Pharmacol. 2015;73:196-200. https://doi.org/10.1016/j.yrtph.2015.06.022.

3. Kim M, Baek HS, Lee M, Park H, Shin SS, Choi DW, et al. Rhododenol and raspberry ketone impair the normal proliferation of melanocytes through reactive oxygen species-dependent activation of GADD45. Toxicol In Vitro. 2016;32:339-46. https://doi.org/10.1016/j.tiv.2016.02.003.

4. Lee J. Further research on the biological activities and the safety of raspberry ketone is needed. NFS J. 2016;2:15-8. https://doi.org/10.1016/j. nfs.2015.12.001.

5. Morimoto C, Satoh Y, Hara M, Inoue S, Tsujita T, Okuda H. Anti-obese action of raspberry ketone. Life Sci. 2005;77:194-204. https://doi. org/10.1016/j.lfs.2004.12.029.
6. Wang L, Meng X, Zhang F. Raspberry ketone protects rats fed high-fat diets against nonalcoholic steatohepatitis. J Med Food. 2012;15:495-503. https://doi.org/10.1089/jmf.2011.1717.

7. Larsen M, Poll L, Callesen O, Lewis M. Relations between the content of aroma compounds and the sensory evaluation of 10 raspberry varieties (Rubus Idaeus L). Acta Agric Scand. 1991;41:447-54. https://doi. org/10.1080/00015129109439927.

8. Wang C, Zheng P, Chen P. Construction of synthetic pathways for raspberry ketone production in engineered Escherichia coli. Appl Microbiol Biotechnol. 2019;103:3715-25. https://doi.org/10.1007/s00253-019-09748 -5 .

9. Vandamme EJ, Soetaert W. Bioflavours and fragrances via fermentation and biocatalysis. J Chem Technol Biotechnol. 2002;77:1323-32. https:// doi.org/10.1002/jctb.722

10. Smith LR. Rheosmin ("raspberry ketone") and zingerone, and their preparation by crossed aldol-catalytic hydrogenation sequences. Chem Educ. 1996;1:1-18. https://doi.org/10.1007/s00897960034a.

11. European Council. Regulation (EC) No 1334/2008 on flavourings and certain food ingredients with flavouring properties for use in and on foods and amending Council Regulation (EEC) No 1601/91, Regulations (EC) No 2232/96 and (EC) No 110/2008 and Directive 2000/13/EC. 2008.

12. Borejsza-Wysocki W, Hrazdina G. Biosynthesis of $p$-hydroxyphenylbutan-2-one in raspberry fruits and tissue cultures. Phytochemistry. 1994;35:623-8. https://doi.org/10.1016/S0031-9422(00)90575-2.

13. Lee D, Lloyd NDR, Pretorius IS, Borneman AR. Heterologous production of raspberry ketone in the wine yeast Saccharomyces cerevisiae via pathway engineering and synthetic enzyme fusion. Microb Cell Fact. 2016:15:1-7. https://doi.org/10.1186/s12934-016-0446-2.

14. Koeduka T, Watanabe B, Suzuki S, Hiratake J, Mano J, Yazaki K. Characterization of raspberry ketone/zingerone synthase, catalyzing the alpha beta-hydrogenation of phenylbutenones in raspberry fruits. Biochem Biophys Res Commun. 2011;412:104-8. https://doi.org/10.1016/j. bbrc.2011.07.052.

15. Kallscheuer N, Vogt M, Stenzel A, Gätgens J, Bott M, Marienhagen J. Construction of a Corynebacterium glutamicum platform strain for the production of stilbenes and (2S)-flavanones. Metab Eng. 2016:38:47-55. https://doi.org/10.1016/j.ymben.2016.06.003.

16. Milke L, Kallscheuer N, Kappelmann J, Marienhagen J. Tailoring Corynebacterium glutamicum towards increased malonyl-CoA availability for efficient synthesis of the plant pentaketide noreugenin. Microb Cell Fact. 2019;18:71. https://doi.org/10.1186/s12934-019-1117-x.

17. Kallscheuer N, Kage H, Milke L, Nett M, Marienhagen J. Microbial synthesis of the type I polyketide 6-methylsalicylate with Corynebacterium glutamicum. Appl Microbiol Biotechnol. 2019;103:9619-31. https://doi. org/10.1007/s00253-019-10121-9.

18. Milke L, Ferreira P, Kallscheuer N, Braga A, Vogt M, Kappelmann J, et al. Modulation of the central carbon metabolism of Corynebacterium glutamicum improves malonyl-CoA availability and increases plant polyphenol synthesis. Biotechnol Bioeng. 2019;116:1380-91. https://doi. org/10.1002/bit.26939.

19. Milke L, Aschenbrenner J, Marienhagen J, Kallscheuer N. Production of plant-derived polyphenols in microorganisms: current state and perspectives. Appl Microbiol Biotechnol. 2018;102:1575-85. https://doi. org/10.1007/s00253-018-8747-5.

20. Hassaninasab A, Hashimoto Y, Tomita-Yokotani K, Kobayashi M. Discovery of the curcumin metabolic pathway involving a unique enzyme in an intestinal microorganism. Proc Natl Acad Sci. 2011;108:6615-20. https:// doi.org/10.1073/pnas.1016217108.

21. Kortmann M, Kuhl V, Klaffl S, Bott M. A chromosomally encoded T7 RNA polymerase-dependent gene expression system for Corynebacterium glutamicum: construction and comparative evaluation at the single-cel level. Microb Biotechnol. 2015:8:253-65. https://doi.org/10.1111/17517915.12236.

22. Blombach B, Riester T, Wieschalka S, Ziert C, Youn JW, Wendisch VF, et al Corynebacterium glutamicum tailored for efficient isobutanol production. Appl Environ Microbiol. 2011;77:3300-10. https://doi.org/10.1128/ AEM.02972-10

23. Sauer U, Canonaco F, Heri S, Perrenoud A, Fischer E. The soluble and membrane-bound transhydrogenases UdhA and PntAB have divergent functions in NADPH metabolism of Escherichia coli. J Biol Chem. 2004;279:6613-9. https://doi.org/10.1074/jbc.M311657200. 
24. Jackson JB. Proton translocation by transhydrogenase. FEBS Lett. 2003;545:18-24. https://doi.org/10.1016/S0014-5793(03)00388-0.

25. Reddy GK, Lindner SN, Wendisch VF. Metabolic engineering of an ATP-neutral Embden-Meyerhof-Parnas pathway in Corynebacterium glutamicum: growth restoration by an adaptive point mutation in NADH dehydrogenase. Appl Environ Microbiol. 2015;81:1996-2005. https://doi org/10.1128/AEM.03116-14.

26. Abe I, Takahashi Y, Morita H, Noguchi H. Benzalacetone synthase. A novel polyketide synthase that plays a crucial role in the biosynthesis of phenylbutanones in Rheum palmatum. Eur J Biochem. 2001;268:3354-9. https://doi.org/10.1046/j.1432-1327.2001.02255.x.

27. Shimokawa Y, Morita H, Abe I. Benzalacetone synthase. Front Plant Sci. 2012;3:57. https://doi.org/10.3389/fpls.2012.00057.

28. Zheng D, Schröder G, Schröder J, Hrazdina G. Molecular and biochemical characterization of three aromatic polyketide synthase genes from Rubus idaeus. Plant Mol Biol. 2001;46:1-15. https://doi.org/10.1023/A:10106 42517738.

29. Zheng D, Hrazdina G. Molecular and biochemical characterization of benzalacetone synthase and chalcone synthase genes and their proteins from raspberry (Rubus idaeus L.). Arch Biochem Biophys. 2008;470:139-45. https://doi.org/10.1016/j.abb.2007.11.013.

30. Kallscheuer N, Vogt M, Bott M, Marienhagen J. Functional expression of plant-derived O-methyltransferase, flavanone 3-hydroxylase, and flavonol synthase in Corynebacterium glutamicum for production of pterostilbene, kaempferol, and quercetin. J Biotechnol. 2017;258:190-6. https://doi. org/10.1016/j.jbiotec.2017.01.006.

31. Kuhn W, Funk H-U, Senft G. Process for the preparation of benzylacetone. US 6,441,242 B1, 2002.

32. Parthasarathy VA, Chempakam B, Zachariah TJ. Chemistry of spices. vol. 32. 2008. https://doi.org/10.4327/jsnfs1949.32.267.

33. Rajan I, Narayanan N, Rabindran R, Jayasree PR, Manish Kumar PR. Zingerone protects against stannous chloride-induced and hydrogen peroxide-induced oxidative DNA damage in vitro. Biol Trace Elem Res. 2013;155:455-9. https://doi.org/10.1007/s12011-013-9801-x.

34. Svetaz LA, Di Liberto MG, Zanardi MM, Suárez AG, Zacchino SA. Efficient production of the flavoring agent zingerone and of both (R)- and (S)zingerols via green fungal biocatalysis. Comparative antifungal activities between enantiomers. Int J Mol Sci. 2014;15:22042-58. https://doi. org/10.3390/ijms151222042.

35. Wagner S, Bader ML, Drew D, de Gier JW. Rationalizing membrane protein overexpression. Trends Biotechnol. 2006;24:364-71. https://doi. org/10.1016/j.tibtech.2006.06.008.

36. Bommareddy RR, Chen Z, Rappert S, Zeng A. A de novo NADPH generation pathway for improving lysine production of Corynebacterium glutamicum by rational design of the coenzyme specificity of glyceraldehyde 3-phosphate dehydrogenase. Metab Eng. 2014;25:30-7. https://doi.org/10.1016/j.ymben.2014.06.005.

37. Glick BR. Metabolic load and heterologous gene expression. Biotechnol Adv. 1995;13:247-61. https://doi.org/10.1016/0734-9750(95)00004-a.

38. Wu G, Yan Q, Jones JA, Tang YJ, Fong SS, Koffas MAG. Metabolic Burden: cornerstones in synthetic biology and metabolic engineering applications. Trends Biotechnol. 2016;34:652-64. https://doi.org/10.1016/j.tibte ch.2016.02.010

39. Keilhauer $\mathrm{C}$, Eggeling L, Sahm H. Isoleucine synthesis in Corynebacterium glutamicum: molecular analysis of the ilvB-ilvN-ilvC operon. J Bacteriol. 1993;175:5595-603. https://doi.org/10.1128/jb.175.17.5595-5603.1993.

40. Bertani G. Studies on lysogenesis. I. The mode of phage liberation by lysogenis Escherichia coli. J Bacteriol. 1951;62:293-300.

41. Green MR, Sambrook J. Molecular cloning: a laboratory manual. 4th ed. Cold Spring Harbor: Cold Spring Harbor Laboratory Press; 2012.

42. Gibson DG, Young L, Chuang R-Y, Venter JC, Hutchison CA, Smith HO. Enzymatic assembly of DNA molecules up to several hundred kilobases. Nat Methods. 2009;6:343-5. https://doi.org/10.1038/nmeth.1318.

43. Niebisch A, Bott M. Molecular analysis of the cytochrome $b c_{1}-a a_{3}$ branch of the Corynebacterium glutamicum respiratory chain containing an unusual diheme cytochrome $c_{1}$. Arch Microbiol. 2001;175:282-94. https:// doi.org/10.1007/s002030100262.

44. Schäfer A, Tauch A, Jaeger W, Kalinowski J, Thierbach G, Pühler A. Small mobilizable multi-purpose cloning vectors derived from the Escherichia coli plasmids pK18 and pK19: selection of defined deletions in the chromosome of Corynebacterium glutamicum. Gene. 1994;145:69-73. https:// doi.org/10.1016/0378-1119(94)90324-7.

45. Eggeling L, Bott M. Handbook of Corynebacterium glutamicum. Boca Raton: CRC Press; 2005. https://doi.org/10.1201/9781420039696.

46. Litsanov B, Brocker M, Bott M. Toward homosuccinate fermentation: metabolic engineering of Corynebacterium glutamicum for anaerobic production of succinate from glucose and formate. Appl Environ Microbiol. 2012;78:3325-37. https://doi.org/10.1128/AEM.07790-11.

47. Gande R, Dover LG, Krumbach K, Besra GS, Sahm H, Oikawa T, et al. The two carboxylases of Corynebacterium glutamicum essential for fatty acid and mycolic acid synthesis. J Bacteriol. 2007;189:5257-64. https://doi. org/10.1128/JB.00254-07

\section{Publisher's Note}

Springer Nature remains neutral with regard to jurisdictional claims in published maps and institutional affiliations.
Ready to submit your research? Choose BMC and benefit from:

- fast, convenient online submission

- thorough peer review by experienced researchers in your field

- rapid publication on acceptance

- support for research data, including large and complex data types

- gold Open Access which fosters wider collaboration and increased citations

- maximum visibility for your research: over $100 \mathrm{M}$ website views per year

At BMC, research is always in progress.

Learn more biomedcentral.com/submissions 